\title{
lodinated contrast for patients with chronic kidney disease-writing on the wall or free for all?
}

\author{
Dadi Helgason ${ }^{1}$, Martin I. Sigurdsson ${ }^{2,3}$ \\ ${ }^{1}$ Internal Medicine Services, Landspitali - The National University Hospital of Iceland, Reykjavik, Iceland; ${ }^{2}$ Division of Anesthesia and Intensive \\ Care Medicine, Landspitali - The National University Hospital of Iceland, Reykjavik, Iceland; ${ }^{3}$ Faculty of Medicine, University of Iceland, Reykjavik, \\ Iceland
}

Correspondence to: Dr. Martin I. Sigurdsson, MD, PhD. Division of Anesthesia and Intensive Care Medicine, Landspitali - The National University Hospital of Iceland, Reykjavik, Iceland. Email: martiningi@gmail.com.

Comment on: Davenport MS, Perazella MA, Yee J, Dillman JR, Fine D, McDonald RJ, Rodby RA, Wang CL, Weinreb JC. Use of Intravenous Iodinated Contrast Media in Patients with Kidney Disease: Consensus Statements from the American College of Radiology and the National Kidney Foundation. Radiology 2020;294:660-8.

Submitted Aug 31, 2020. Accepted for publication Sep 09, 2020.

doi: 10.21037/qims-2020-27

View this article at: http://dx.doi.org/10.21037/qims-2020-27

Acute kidney injury (AKI) is associated with adverse outcomes, including worse short- and long-term mortality, increased length of hospital stay and development of chronic kidney disease (CKD) (1). Iodinated contrast has been associated with AKI since its use began in the middle of the 20th century, termed contrast induced nephropathy and later contrast induced acute kidney injury (CI-AKI). Studies on the underlying pathogenesis have mainly been limited to animal models (2). With the development of newer contrast types, low osmolar contrast media and isoosmolar contrast media that have replaced high osmolar contrast media, the importance of contrast in development of AKI has been questioned (3). The term contrast associated AKI (CA-AKI) or post-contrast exposure AKI have now been proposed since other factors such as age, CKD and other comorbidities have been shown to increase the risk of $\mathrm{AKI}(4,5)$.

Iodinated contrast media is widely used in daily medical practice both in invasive procedures such as angiographies and non-invasive imaging studies including computed tomography. Because of the risk of AKI following contrast exposure, clinicians are often hesitant to use it for patients with CKD.

There is a lack of randomized control trials in this field but recent retrospective studies have suggested that intravenous contrast does not increase the risk of developing AKI, even in patients with advanced CKD (3). Current guidelines do not give a clear guidance for clinicians considering contrast use in patients with CKD. The paper by Davenport et al. "Use of Intravenous Iodinated Contrast Media in Patients with Kidney Disease: Consensus Statements from the American College of Radiology and the National Kidney Foundation" (6) aims to standardize and improve the care of CKD patients that require studies that involve iodinated contrast.

The consensus is limited to intravenous contrast use and does not cover the intraarterial use, for example for coronary angiographies. The authors review the literature, first by covering definitions and classifications of CIAKI and CA-AKI, followed by an overview of diagnosis, risk assessment and prophylactic treatment. The authors propose fifteen consensus statements based on existing evidence and compare them to guidelines from American College of Radiology (ACR)(4) and Kidney Disease Improving Global Outcomes (KDIGO) (5) regarding CI$\mathrm{AKI}$ and CA-AKI.

The key points from the statements are:

* KDIGO criteria for AKI should be used to diagnose CI-AKI and CA-AKI. Several definitions have been used to define AKI over the years and although the 
consensus publication for AKI, the KDIGO criteria, has increased consistency and allowed comparisons between AKI studies, there is still been a discrepancy in definitions of AKI following contrast exposure.

* The authors make a distinction between CA-AKI and CI-AKI in their risk assessment. The risk of CA-AKI is low in patients with low stage CKD but increases with growing stages and is as high as 30\% in patients with estimated glomerular filtration rate (eGFR) less than $30 \mathrm{~mL} / \mathrm{min} / 1.73 \mathrm{~m}^{2}$. On the other hand, the risk of CI-AKI is uncertain since there are no prospective studies that compare contrast exposure with no contrast. Some studies have questioned the true existence of CI-AKI while others have shown an increased risk in patients with eGFR less than $30 \mathrm{~mL} / \mathrm{min} / 1.73 \mathrm{~m}^{2}$.

* Other risk factors for CA-AKI include diabetes, hypotension, hypoperfusion of the kidneys and nephrotoxic agents.

* There does not seem to be a clinically significant difference in the risk of CI-AKI between lowosmolarity and isoosmotic contrast media, but high-osmolarity contrast media should not be used intravenously.

* Prophylaxis with intravenous isotonic fluid is indicated in patients with AKI, patients with eGFR less than $30 \mathrm{~mL} / \mathrm{min} / 1.73 \mathrm{~m}^{2}$ who are not receiving maintenance dialysis and patients on dialysis with residual kidney function. Prophylaxis may be considered in high risk patients with eGFR between $30-44 \mathrm{~mL} / \mathrm{min} / 1.73 \mathrm{~m}^{2}$. The dose and rate of resuscitation is uncertain and differs based on patients' condition and comorbidity. Other prophylactic measures such as n-acetylcysteine have not shown clear benefit.

* Non-essential nephrotoxic agents should be withheld prior to contrast exposure. The data regarding renin-angiotensin-aldosterone system inhibitors is conflicting but the authors recommend that the drugs should be discontinued 48 hours prior to elective CT.

* Contrast media dose should not be reduced below a known diagnostic threshold in patients at high risk of CI-AKI, which had previously been recommended in the KDIGO guidelines.

In summary, it is now accepted that the risk of AKI following contrast exposure is lower than previously been assumed, and mostly affects patients with advanced CKD.
Contrast is only one of many risk factors for AKI in these patients and the term CA-AKI is now being used rather than CI-AKI. Imaging studies using intravenous contrast can be vital in diagnosing an underlying condition, and withholding contrast to patients considered at risk for CAAKI could lead to a delay in diagnosis and treatment of their underlying condition, that could prove more harmful than the contrast. However, in patients with very advanced $\mathrm{CKD}$, the possible risk of $\mathrm{AKI}$ expediting the progression to end-stage renal disease and requirement for renal replacement therapy cannot be completely overlooked. In those individuals, a careful risk/benefit assessment is required.

\section{Acknowledgments}

Funding: None.

\section{Footnote}

Provenance and Peer Review: This article was commissioned by the editorial office, Quantitative Imaging in Medicine and Surgery. The article did not undergo external peer review.

Conflicts of Interest: Both authors have completed the ICMJE uniform disclosure form (available at http://dx.doi. org/10.21037/qims-2020-27). The authors have no conflicts of interest to declare.

Open Access Statement: This is an Open Access article distributed in accordance with the Creative Commons Attribution-NonCommercial-NoDerivs 4.0 International License (CC BY-NC-ND 4.0), which permits the noncommercial replication and distribution of the article with the strict proviso that no changes or edits are made and the original work is properly cited (including links to both the formal publication through the relevant DOI and the license). See: https://creativecommons.org/licenses/by-nc-nd/4.0/.

\section{References}

1. Coca SG, Yusuf B, Shlipak MG, Garg AX, Parikh CR. Long-term risk of mortality and other adverse outcomes after acute kidney injury: a systematic review and metaanalysis. Am J Kidney Dis 2009;53:961-73.

2. Tumlin J, Stacul F, Adam A, Becker CR, Davidson C, Lameire N, McCullough PA; CIN Consensus Working Panel. Pathophysiology of contrast-induced nephropathy. 
Am J Cardiol 2006;98:14K-20K.

3. McDonald RJ, McDonald JS, Bida JP, Carter RE, Fleming CJ, Misra S, Williamson EE, Kallmes DF. Intravenous contrast material-induced nephropathy: causal or coincident phenomenon? Radiology 2013;267:106-18.

4. American College of Radiology. Manual on contrast media. Version 10.3. American College of Radiology. Available online: https://www.acr.org/Clinical-Resources/ Contrast-Manual

5. Kidney Disease Improving Global Outcomes: (KDIGO)

Cite this article as: Helgason D, Sigurdsson MI. Iodinated contrast for patients with chronic kidney disease-writing on the wall or free for all? Quant Imaging Med Surg 2021;11(2):876-878. doi: 10.21037/qims-2020-27
Acute Kidney Injury Work Group. KDIGO Clinical Practice Guideline for Acute Kidney Injury. Kidney inter 2012;2:1-138.

6. Davenport MS, Perazella MA, Yee J, Dillman JR, Fine D, McDonald RJ, Rodby RA, Wang CL, Weinreb JC. Use of Intravenous Iodinated Contrast Media in Patients with Kidney Disease: Consensus Statements from the American College of Radiology and the National Kidney Foundation. Radiology 2020;294:660-8. 